

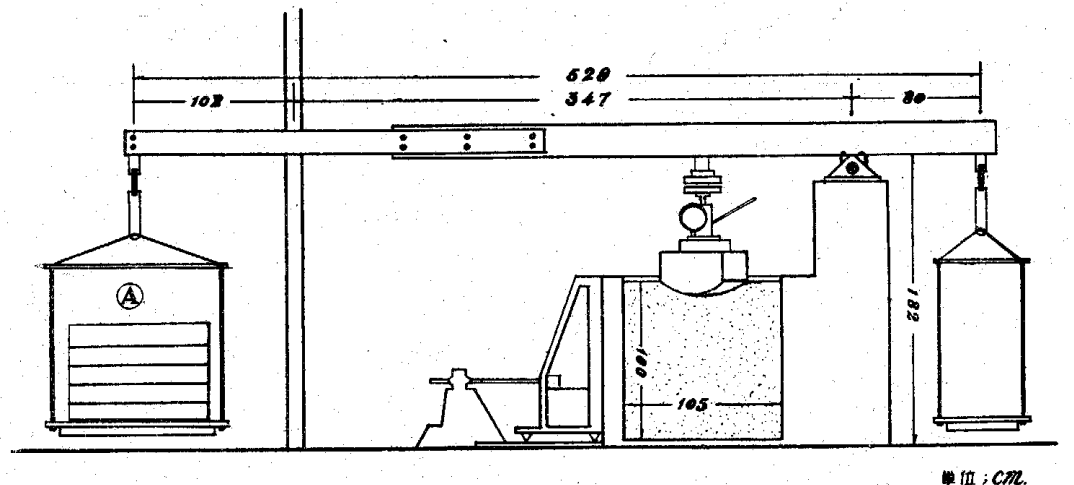

第 1 図一a

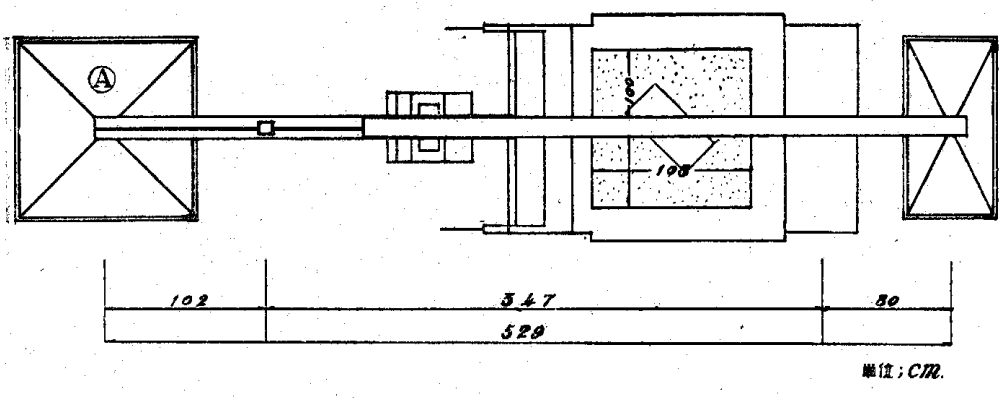

第 1 図一b

乾燥密度 $r_{d}=1.69$ 相対密度 $D_{r}=0.96$

同密度に於ける剪断試験結果

$$
\varphi=53^{\circ} 17^{\prime}, \quad \tan \varphi=1.34, \quad c=0
$$

III）使用土圧計 第 2 淐のような strain gauge (unbonded type) 利用の 压力計 (最大能力 $50 \mathrm{t} / \mathrm{m}^{2}$ 及び $\left.100 \mathrm{t} / \mathrm{m}^{2}\right)$ を予め caribrate して掠き、電気 抵抗変化と圧力との関係の 較正係数を算定して招い た。

第 3 図はこの圧力計（受 压面径 $30 \mathrm{~mm}$ 東洋測器製) の説明図で、抵抗線 $A, B$, C,D はブリッジ組まれ て挍り、支柱の間を他に接 着する事なく張られてい

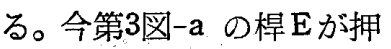
される先 $\mathrm{A} \cdot \mathrm{C}$ は伸び $\mathrm{B} \cdot \mathrm{D}$ 以縮み、電気抵抗が変化す る。この場合の感度は接着

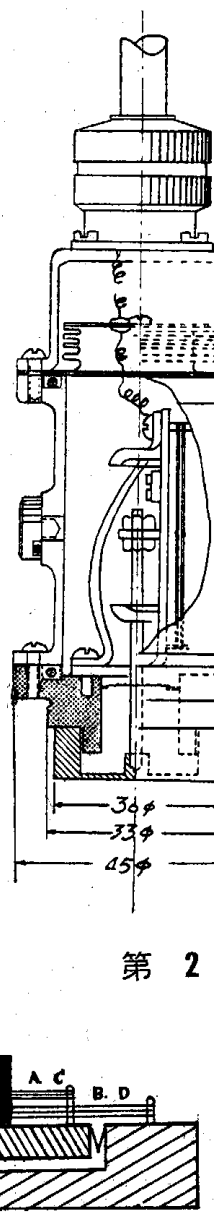

型より高く（出力 $1 \mathrm{~kg} / \mathrm{cm}^{2}$ で $2 \mathrm{mv} / \mathrm{v}$, フルスケール $2000 \times 10^{-6}$ strain) 小さな 圧力子測定される。殊飞受圧面が小さい ので模型実験で適していると思われる。

IV) 測定方法 先ゔ模型を設置す る前と土圧計の読みをとり、模型、ジャ ッキ等を据克つけた後 dial gauge 取 りつけ、そのよみを0とした。次に I 形 鎆を通して®部にのせた荷重及び上階ス ラブをオイルジャッキで押上げ、これを 反力として模型を圧する。この圧力はオ イルジャッキに装置されたブルドン管式 圧力計で読みとつた。荷重は円筒体及び 矩形板の場合 $0.5 \mathrm{t}$ づつ最終荷重 $3.0 \mathrm{t}$ 迄、球面体及び円形板の場合飞は $0.8 \mathrm{t}$ づつ最終荷重 4.8 t 迄加光た。接地圧及 び沈下量の測定は各荷重每に行い、最初 の読みとの差を求めた。測定は各荷重載 荷後、各沈下測定点の沈下量が 5 分間で 1/100 mm 以下になつた時に読みとつた ものである。又この実験は各模型について 3 回づつ行つ た。今後は圧力計の記録並びそ載荷はすべて別紙発表の 自動装置で行う積りである。

\section{§5. 実駼結果}

第 1 表〜第 6 表及び第 4 図 第 9 図々示したのは前述 の方法にもとづいて行つた実験結果の中その代表的なる のである。図中 $\times$ 印は沈下測定点、○印は土压計取付け 位置を示し、分布図横軸上の数字は土圧計取付け位置の 中、グラフと表わしたもの番号である。又分布図右側 の数字はオイルジャッキで加えた載荷重、（）内は模 型及びオイルジャッキ等を設置した時の重量を加えた水 平単位面積当りの荷重を表わしている。

これ迄平板に対する接地圧の分布状態は昔からKögler 等によつて既に研究されて招り、これによれば砂地盤に 於ける接地圧分布は中央が大きく端部に行くに従つて小 さくなる事が知られている。本実験を通じてみてもこの 事は明らかであり、特に曲面体に於ては端部で著しく接 地圧が小さくなつているのが見られる。

尚一模型で対称位置の接地圧が買つた値を示したのは 荷重の偏心、砂の密度の不均等性、並びそこれ等に帰因 する不同沈下によるるのではないかと考完られる。

本実験汇関して多大の御援助を頂いた大成建設 K. K. (a)

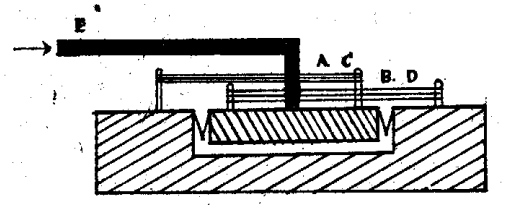

第 3 図

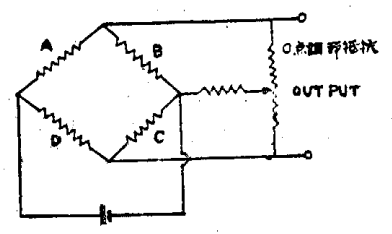

(b) 
第 1 表 円筒体中央部

\begin{tabular}{|c|c|c|c|c|c|c|c|}
\hline & & 4.65 & 8.65 & 12,65 & 16,65 & 20.65 & 24.65 \\
\hline $\begin{array}{c}\text { 接 } \\
\text { 地 } \\
\text { 圧 } \\
\left(\mathrm{t} / \mathrm{m}^{2}\right)\end{array}$ & $\begin{array}{l}\text { No. } 3 \\
\text { No. } 6 \\
\text { No. } 7 \\
\text { No. } 8 \\
\text { No. } 10\end{array}$ & $\begin{array}{l}.82 \\
3.44 \\
5.88 \\
8.58 \\
2.34\end{array}$ & $\begin{array}{r}11.19 \\
5.59 \\
9.25 \\
18.85 \\
4.34\end{array}$ & $\begin{array}{r}17.89 \\
8.30 \\
13.44 \\
25.33 \\
6.47\end{array}$ & $\begin{array}{r}21.44 \\
10.19 \\
18.93 \\
33.35 \\
8.03\end{array}$ & $\begin{array}{r}28.34 \\
13.00 \\
23.42 \\
39.59 \\
8.73\end{array}$ & $\begin{array}{l}33.71 \\
15.48 \\
27.91 \\
44.96 \\
10.01\end{array}$ \\
\hline $\begin{array}{c}\text { 沈 } \\
\text { 量 } \\
\text { 量 }\end{array}$ & $\begin{array}{c}\mathrm{A} \\
\mathrm{B} \\
\mathrm{C} \\
\mathrm{D}^{\text {平 }} \text { 均 }\end{array}$ & $\begin{array}{l}0.58 \\
0.73 \\
0.73 \\
0.52 \\
0.64\end{array}$ & $\begin{array}{l}1.41 \\
1.57 \\
1.50 \\
1.23 \\
1.43\end{array}$ & $\begin{array}{l}2.23 \\
2.34 \\
2.19 \\
1.92 \\
2.17\end{array}$ & $\begin{array}{l}2.82 \\
3.09 \\
3.00 \\
2.39 \\
2.83\end{array}$ & $\begin{array}{l}3.09 \\
3.89 \\
4.01 \\
2.91 \\
3.48\end{array}$ & $\begin{array}{l}3.62 \\
4.63 \\
4.84 \\
3.52 \\
4.15\end{array}$ \\
\hline
\end{tabular}

第 3 表 円筒体端部

\begin{tabular}{|c|c|c|c|c|c|c|c|}
\hline 7 & 87 & 4.62 & 8.62 & 12.62 & 16.62 & 20.62 & 24.62 \\
\hline $\begin{array}{c}\text { 接 } \\
\text { 地 } \\
\text { 压 } \\
\left(\mathbf{t} / \mathrm{m}^{2}\right)\end{array}$ & $\begin{array}{l}\text { No. } 1 \\
\text { No. } 2 \\
\text { No. } 3 \\
\text { No. } 6 \\
\end{array}$ & $\begin{array}{l}1.15 \\
5.12 \\
9.28 \\
0.43 \\
\end{array}$ & $\begin{array}{r}1.28 \\
9.12 \\
15.87 \\
2.34 \\
\end{array}$ & $\begin{array}{r}1.79 \\
12.71 \\
22.49 \\
3.50\end{array}$ & $\begin{array}{r}1.63 \\
15.59 \\
26.18 \\
4.40\end{array}$ & $\begin{array}{r}1.68 \\
19.99 \\
32.75 \\
5.29\end{array}$ & $\begin{array}{r}3.12 \\
26.39 \\
39.95 \\
5.32\end{array}$ \\
\hline $\begin{array}{c}\text { 沈 } \\
\text { 量 } \\
(\mathrm{mm}) \\
\end{array}$ & $\begin{array}{c}\mathrm{A} \\
\mathrm{B} \\
\mathrm{C} \\
\mathrm{D} \\
\text { 平 均 }\end{array}$ & $\begin{array}{l}0.51 \\
0.46 \\
0.28 \\
0.28 \\
0.38 \\
\end{array}$ & $\begin{array}{l}0.98 \\
1.03 \\
0.79 \\
0.66 \\
0.87 \\
\end{array}$ & $\begin{array}{l}1.49 \\
1.56 \\
1.17 \\
0.99 \\
1.30 \\
\end{array}$ & $\begin{array}{l}1.97 \\
1.99 \\
1.47 \\
1.33 \\
1.69\end{array}$ & $\begin{array}{l}2.53 \\
2.49 \\
1.81 \\
1.67 \\
2.13\end{array}$ & $\begin{array}{l}3.27 \\
3.08 \\
2.07 \\
2.08 \\
2.63\end{array}$ \\
\hline
\end{tabular}

第 2 表 矩形板中央部

\begin{tabular}{|c|c|c|c|c|c|c|c|}
\hline \multicolumn{2}{|c|}{ 䄆重 $\left(\mathrm{t} / \mathrm{m}^{2}\right)$} & 4.82 & 8.82 & 12.82 & 16.82 & 20.82 & 24.82 \\
\hline $\begin{array}{c}\text { 接 } \\
\text { 地 } \\
\text { 压 } \\
\left(\mathrm{t} / \mathrm{m}^{2}\right)\end{array}$ & $\begin{array}{l}\text { No. } 3 \\
\text { No. } 6 \\
\text { No. } 7 \\
\text { No. } 8 \\
\text { No. } 12 \\
\end{array}$ & $\begin{array}{l}6.50 \\
2.29 \\
8.15 \\
9.23 \\
3.99 \\
\end{array}$ & $\begin{array}{r}11.25 \\
5.37 \\
13.74 \\
17.26 \\
8.29 \\
\end{array}$ & $\begin{array}{l}16.22 \\
10.39 \\
18.92 \\
25.33 \\
12.90 \\
\end{array}$ & $\begin{array}{l}20.86 \\
13.17 \\
23.60 \\
32.83 \\
17.45\end{array}$ & $\begin{array}{l}24.98 \\
19.10 \\
28.25 \\
39.38 \\
21.73\end{array}$ & $\begin{array}{l}29.09 \\
24.15 \\
32.87 \\
45.14 \\
26.37\end{array}$ \\
\hline $\begin{array}{c}\text { 沈 } \\
\text { 量 } \\
(\mathrm{mm})\end{array}$ & $\begin{array}{c}\mathrm{A} \\
\mathrm{B} \\
\mathrm{C} \\
\mathrm{D}^{2}\end{array}$ & $\begin{array}{l}0.59 \\
0.73 \\
1.06 \\
0.70 \\
0.76\end{array}$ & \begin{tabular}{|l|}
1.28 \\
1.45 \\
1.63 \\
1.37 \\
1.43
\end{tabular} & $\begin{array}{l}1.90 \\
1.98 \\
2.16 \\
1.98 \\
2.01\end{array}$ & $\begin{array}{l}2.44 \\
2.47 \\
2.64 \\
2.49 \\
2.51\end{array}$ & $\begin{array}{l}2.89 \\
2.91 \\
3.10 \\
3.01 \\
2.98\end{array}$ & $\begin{array}{l}3.45 \\
3.43 \\
3.65 \\
3.55 \\
3.52\end{array}$ \\
\hline
\end{tabular}
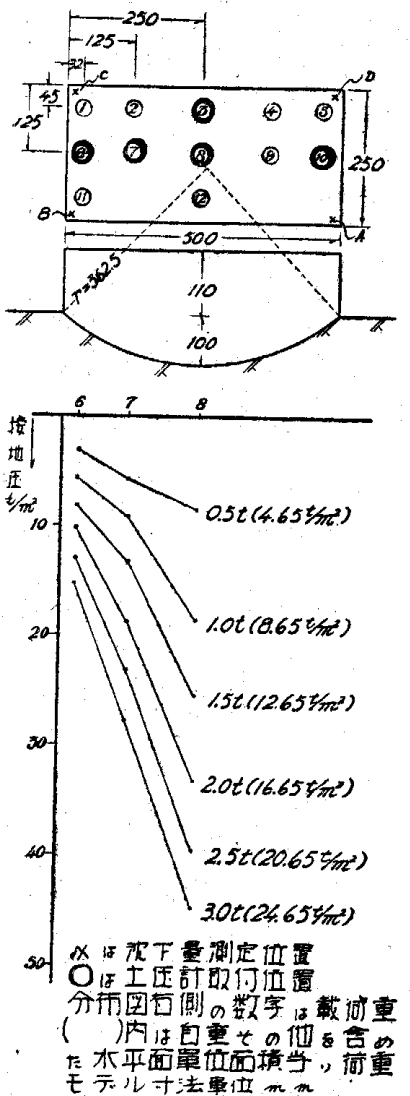

第 4 図 円筒体中央部
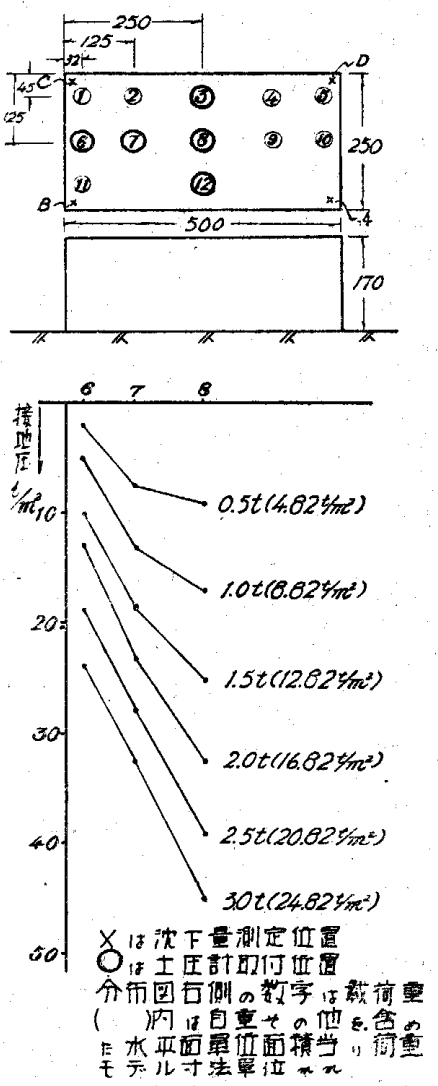

第 5 図 矩形板中央部

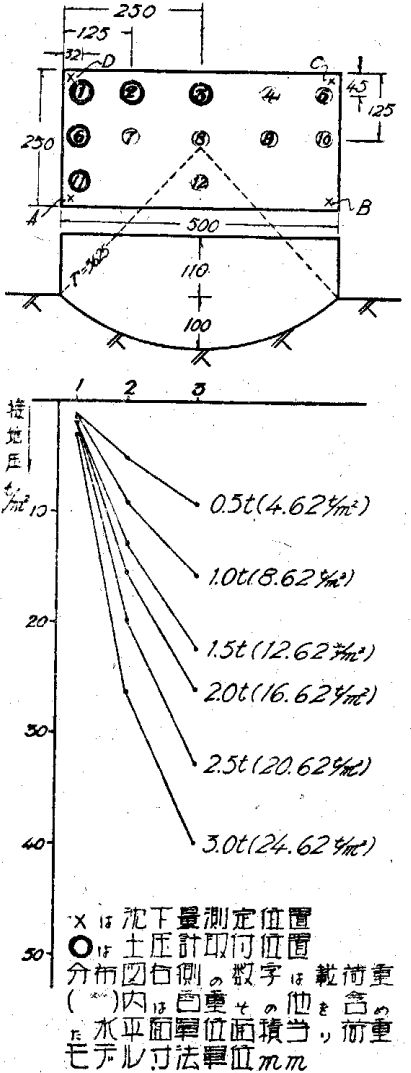

第 6 図" 筒体端部 
第 4 表 矩形板端部

\begin{tabular}{|c|c|c|c|c|c|c|c|}
\hline 荷重 $\left(\mathrm{t} / \mathrm{m}^{2}\right)$ & 重 $\left(\mathrm{t} / \mathrm{m}^{2}\right)$ & 4.79 & 8.79 & 12.79 & 16.79 & 20.79 & 24.79 \\
\hline & No. 1 & 1.74 & 4.18 & 6.59 & 9.07 & 11.51 & 13.48 \\
\hline & No. 2 & 5.43 & 11.28 & 16.71 & 22.29 & 27.47 & 32.86 \\
\hline & No. 3 & 7.02 & 13.59 & 19.88 & 25.85 & 31.66 & 38.06 \\
\hline 圧 & No. 6 & 2.75 & 5.57 & 9.00 & 12.84 & 16.56 & 20.82 \\
\hline$\left(t / m^{2}\right)$ & No. 11 & 2.29 & 5.08 & 9.32 & 13.89 & 18.04 & 22.86 \\
\hline & $\mathrm{A}$ & 1.20 & 2.20 & 3.07 & 3.87 & 4.52 & 5.36 \\
\hline & $\mathrm{B}$ & 0.63 & 1.61 & 2.34 & 3.06 & 3.71 & 4.45 \\
\hline & $\mathrm{C}$ & 0.75 & 1.63 & 2.33 & 3.02 & 3.64 & 4.32 \\
\hline 旦 & $\widehat{D}$ & 1.21 & 2.16 & 2.97 & 3.68 & 4.35 & 5.09 \\
\hline$(\mathrm{mm})$ & 平 均 & 0.95 & 1.90 & 2.68 & 3.41 & 4.06 & 4.81 \\
\hline
\end{tabular}

第 6 表 円，形 板

\begin{tabular}{|c|c|c|c|c|c|c|c|}
\hline \multicolumn{2}{|c|}{$\underbrace{}_{\text {位 }}{ }^{\text {荷重 }}\left(\mathrm{t} / \mathrm{m}^{2}\right)$} & 4.71 & 8.79 & 12.86 & 16.93 & 21.01 & 25.08 \\
\hline $\begin{array}{c}\text { 接 } \\
\text { 地 } \\
\left(\mathrm{t} / \mathrm{m}^{2}\right) \\
\end{array}$ & $\begin{array}{ll}\text { No. } 1 \\
\text { No. } & 2 \\
\text { No. } & 3 \\
\text { No. } & 4 \\
\text { No. } & 5\end{array}$ & \begin{tabular}{l|}
0.60 \\
2.68 \\
7.46 \\
7.34 \\
0.62 \\
\end{tabular} & $\begin{array}{r}2.45 \\
5.36 \\
13.41 \\
14.17 \\
2.03\end{array}$ & \begin{tabular}{r|}
5.34 \\
9.80 \\
19.23 \\
20.01 \\
4.56 \\
\end{tabular} & $\begin{array}{r}8.87 \\
13.48 \\
25.48 \\
26.12 \\
6.70\end{array}$ & $\begin{array}{r}13.67 \\
18.28 \\
30.45 \\
30.13 \\
8.72 \\
\end{array}$ & $\begin{array}{l}17.8 \\
23.64 \\
35.06 \\
34.65 \\
10.5 \\
\end{array}$ \\
\hline $\begin{array}{l}\text { 沈 } \\
\text { 量 } \\
\text { mm }\end{array}$ & $\begin{array}{c}\mathrm{A} \\
\mathrm{B} \\
\mathrm{C} \\
\mathrm{D} \\
\text { 平 均 }\end{array}$ & $\begin{array}{l}0.80 \\
0.46 \\
0.70 \\
0.12 \\
0.52\end{array}$ & \begin{tabular}{|l|}
1.38 \\
2.32 \\
1.53 \\
0.64 \\
1.47
\end{tabular} & $\begin{array}{l}1.99 \\
3.00 \\
2.18 \\
1.17 \\
2.09\end{array}$ & $\begin{array}{l}2.34 \\
3.63 \\
2.76 \\
1.57 \\
2.58\end{array}$ & $\begin{array}{l}2.71 \\
4.11 \\
3.41 \\
2.14 \\
3.09\end{array}$ & $\begin{array}{l}3.11 \\
4.56 \\
3.93 \\
2.64 \\
3.56\end{array}$ \\
\hline
\end{tabular}

第 5 表 球 面 体

\begin{tabular}{|c|c|c|c|c|c|c|c|}
\hline \multicolumn{2}{|c|}{$S_{\text {位 }}$ 荷重 $\left(\mathbf{t} / \mathrm{m}^{2}\right)$} & 4.67 & 8.74 & 12.82 & 16.89 & 20.97 & 25.04 \\
\hline $\begin{array}{c}\text { 接 } \\
\text { 地 } \\
\text { 圧 } \\
\left(\mathrm{t} / \mathrm{m}^{2}\right)\end{array}$ & $\begin{array}{l}\text { No. } 1 \\
\text { No. } 2 \\
\text { No. } 3 \\
\text { No. } 4 \\
\text { No. } 5\end{array}$ & $\begin{array}{l}3.74 \\
5.40 \\
7.82 \\
6.41 \\
2.46\end{array}$ & $\begin{array}{r}6.49 \\
9.45 \\
15.88 \\
10.84 \\
4.15\end{array}$ & $\begin{array}{r}8.28 \\
12.08 \\
23.57 \\
15.08 \\
5.80\end{array}$ & $\begin{array}{r}10.43 \\
16.20 \\
31.86 \\
19.99 \\
7.62\end{array}$ & $\begin{array}{l}11.08 \\
19.35 \\
39.33 \\
26.38 \\
10.10\end{array}$ & $\begin{array}{l}12.15 \\
22.50 \\
45.93 \\
32.02 \\
12.49\end{array}$ \\
\hline $\begin{array}{l}\text { 沈 } \\
\text { 量 } \\
(\mathrm{mm})\end{array}$ & $\begin{array}{c}\mathrm{A} \\
\mathrm{B} \\
\mathrm{C} \\
\mathrm{D}\end{array}$ & $\begin{array}{l}2.40 \\
0.44 \\
0.67 \\
0.75 \\
0.50 \\
0.59\end{array}$ & $\begin{array}{l}1.10 \mid \\
1.07 \\
1.44 \\
1.65 \\
1.26 \\
1.36\end{array}$ & $\begin{array}{l}1.48 \\
2.07 \\
2.38 \\
1.66 \\
1.90\end{array}$ & $\begin{array}{l}2.09 \\
2.65 \\
3.07 \\
2.31 \\
2.53\end{array}$ & $\begin{array}{r}2.45 \\
2.97 \\
3.69 \\
3.02 \\
3.03\end{array}$ & $\begin{array}{l}2.99 \\
3.32 \\
4.31 \\
3.75 \\
3.59\end{array}$ \\
\hline
\end{tabular}
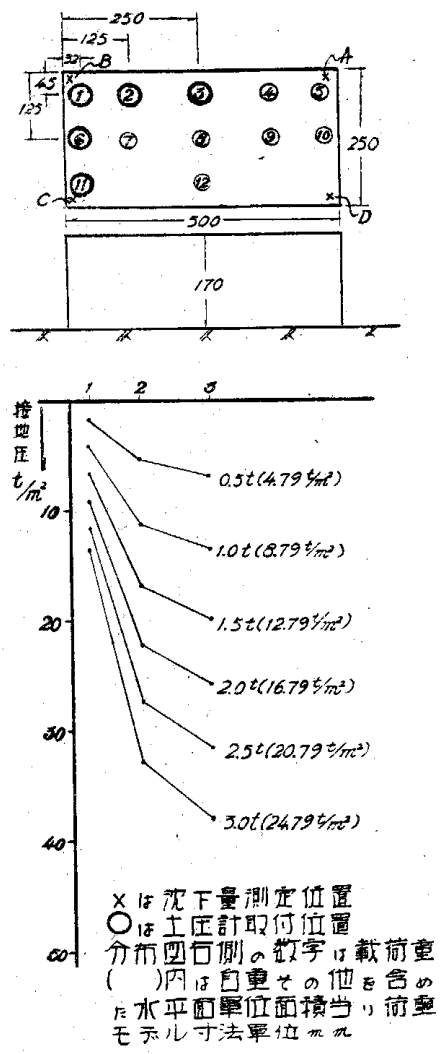

第 7 図 矩形板端部

特わりに実験及び製図等に協力してくれた日大建築学 科 4 年栗原武、今野知則、山口正、畑野弘治、田中修身 斎藤悌、長谷川金重、浅田敏雄、小口章夫、赤松三明及 び日大建築土質工学研究会員の諸君に感謝する。
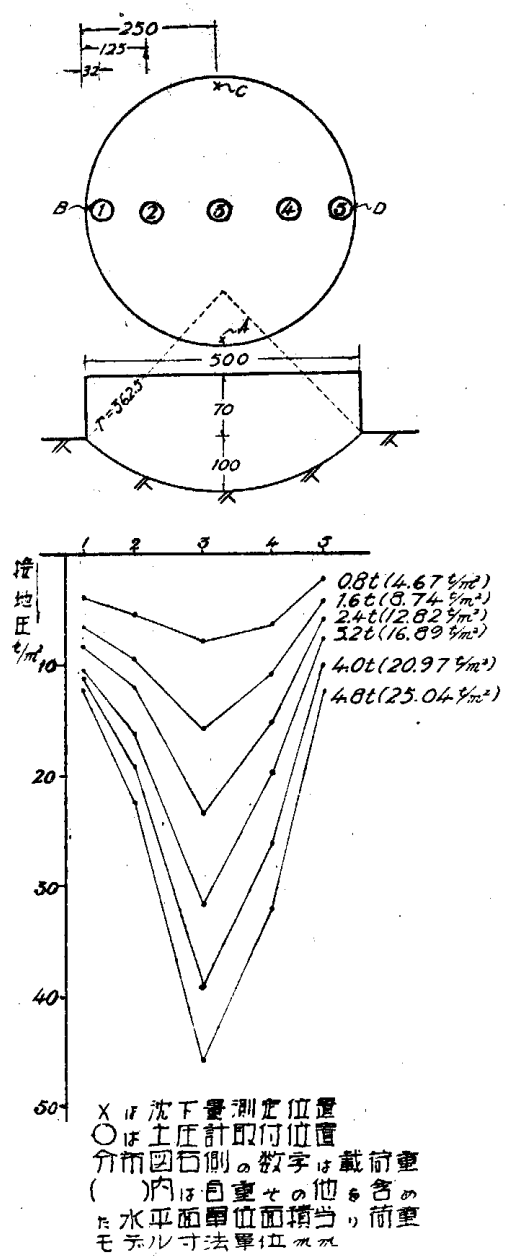

第 8 図 球 面 体
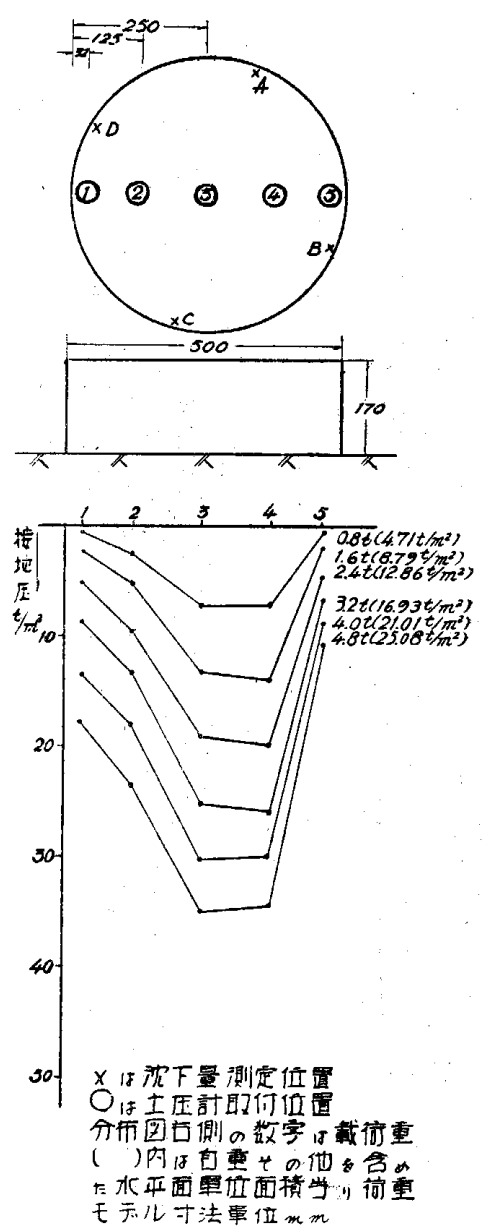

第 9 図円形 板 